\title{
Solubility of zinc oxide-eugenol and calcium hydroxide cements in simulated dentinal fluid
}

\author{
C. F. DRISCOLL, G. D. WOOLSEY*, T. G. REDDY† and \\ R. G. CRAIG $\neq$ U.S. Army Dental Activity, Fort Leavenworth, Kansas, \\ *Fort Hood, Texas and $\dagger$ Fort Knox, Kentucky and $\ddagger$ University of Michigan, \\ School of Dentistry, Ann Arbor, Michigan, U.S.A.
}

\section{Summary}

The solubility of four dental cement bases was measured in simulated dentinal fluid and distilled water to evaluate the relevancy of the American Dental Association solubility test for cement bases in contact with vital dentine. A simulated dentinal fluid was formulated utilizing glucose, distilled water, and sterile human plasma. Cement-base samples were immersed in either distilled water or simulated dentinal fluid at $37^{\circ} \mathrm{C}$ in a shaker water-bath for 1,2 , or 3 months. Weight loss values were compared utilizing a three-way analysis of variance. Zinc oxide-eugenol cements were significantly more soluble in simulated dentinal fluid than distilled water, while the calcium hydroxide cement bases were significantly more soluble in distilled water than simulated dentinal fluid.

\section{Introduction}

The solubility or resistance to disintegration of dental cements is an important criterion in assessing the quality of materials to be used as bases or liners in dental restorations. The American National Standards Institute (ANS)/American Dental Association (ADA) solubility tests in specifications 8, 9, 21 and 30 have been criticized by Pulver \& Rossington (1970), Wilson (1976), and McCabe (1982) for: (i) using distilled water rather than oral fluids, (ii) the length of the testing period (1 week) and (iii) the lack of agitation during the test.

Lewin (1980) had observed that some dental cement bases disintegrate under existing restorations and that the traditional solubility measurements could not explain the loss of these cement bases during clinical service. A possible explanation for this disintegration is the presence and contact of dentinal fluid from the underlying dentine tubules.

Walls, McCabe \& Murray (1985) developed an erosion test in which they alternated the cements in $0.1 \mathrm{~m}$ sodium lactate/lactic acid buffer at $\mathrm{pH} 4.0$ and distilled water at $\mathrm{pH} 5 \cdot 5$. The values correlated with in vivo observations for acid/ base cements such as silicate, zinc phosphate, zinc polyacrylate and glass ionomer.

Stuben \& Kreudenstein (1956) have determined the free amino acid content in dentinal fluid compared to blood and found one-half the reducing substance in the former. In a later paper by Kreudenstein (1958) the concentration of protein in dental lymph was reported to be $0 \cdot 15 \mathrm{~g} \%$.

Correspondence: Colonel Gerald D. Woolsey, Fixed Prosthodontics, Dental Clinic No. 6, U.S.A. DENTAC, Fort Hood, Texas 76542, U.S.A. 
Haldi, Wynn \& Culpepper (1961) described the principal chemical components in the dentinal fluid of dogs by placing capillary tubes through the enamel into the dentine, avoiding contact with the pulp. The clear, somewhat viscous fluid had a chemical composition similar to that of the blood plasma of the same animal, with the glucose concentration in the dentinal fluid being the same as that of the arterial plasma and slightly less than in the venous plasma. However, the protein concentration in the dentinal fluid was about one-fifth of that in the blood plasma.

The general lack of correlation of the laboratory tests for solubility of cements with usage tests, except for acid/base cements in the test by Walls et al. (1985), led to the evaluation of the solubility of zinc oxide-eugenol and calcium hydroxide base cements in a simulated dentinal fluid and a comparison of these values with those obtained using the ADA specification no. 8 (1986) solubility test in distilled water.

\section{Materials and methods}

The simulated dentinal fluid was prepared using human blood plasma and a composition based on the data of Haldi et al. (1961). Human plasma was diluted with sterile water in a 1:5 ratio and glucose was added to achieve an $85 \mathrm{mg} \%$ solution. The solution was then sterilized by filtration through a $0.22 \mu \mathrm{m}$ millipore filter under sterile conditions in a laminar flow hood.

Discs of the zinc oxide-eugenol (Fynal and Cavitec) and calcium hydroxide (Dycal and Life) cement base materials (Table 1), $20 \mathrm{~mm}$ diameter and $2 \mathrm{~mm}$ thick, were fabricated in stainless steel moulds. Preweighed stainless steel wires were embedded in the discs during fabrication to assist in the handling of the samples, and identifying loops were placed in the wire prior to immersion.

Table 1. Dental cement bases and base to catalyst ratios used in the testing

\begin{tabular}{llrr}
\hline Base & Manufacturer & Batch no. & Base $/$ catalyst ratio \\
\hline Fynal & L.D. Caulk Co., Milford, DE, U.S.A. & P012084 & $1.5 \mathrm{~g} / 0.5 \mathrm{ml}$ \\
Cavitec & Kerr/Sybron Corp., Romulus, MI, U.S.A. & L113083 & \\
Dycal & L.D. Caulk Co. & 0227841348 & $1.5 \mathrm{~g} / 0.6 \mathrm{~g}$ \\
Life & Kerr Div. & 0229842340 & $1.17 \mathrm{~g} / 1.00 \mathrm{~g}$ \\
\end{tabular}

Six-inch Boston round bottles containing custom-made stainless steel bracing inserts were used to hold the samples in the simulated dentinal fluid or distilled water.

The discs were weighed and gas-sterilized with ethylene oxide for $24 \mathrm{~h}$ and then degassed for the same period of time. For each month of the study eighteen samples were fabricated for each brand of material (three bottles of three samples in simulated dentinal fluid and three bottles of three samples in distilled water). The bottles were filled with $100 \mathrm{ml}$ of either simulated dentinal fluid or distilled water. Strict adherence to sterile techniques was observed to prevent bacterial contamination.

The type of fluid and length of immersion for each sample set in the study was determined using a table of random numbers. The bottles and their samples were placed in a shaker water-bath and maintained at 30 r.p.m. and $37^{\circ} \mathrm{C}$. After 1 month, 
Table 2. Percentage weight loss of cement bases after immersion in simulated dentinal fluid and distilled water

\begin{tabular}{|c|c|c|c|c|c|c|c|c|c|c|c|c|}
\hline \multirow{2}{*}{$\begin{array}{r}\text { Material: } \\
\text { Immersion time } \\
\text { (months): } \\
\text { Immersion media }\end{array}$} & \multicolumn{3}{|c|}{ Cavitec } & \multicolumn{3}{|c|}{ Fynal } & \multicolumn{3}{|r|}{ Dycal } & \multicolumn{3}{|r|}{ Life } \\
\hline & 1 & 2 & 3 & 1 & 2 & 3 & 1 & 2 & 3 & 1 & 2 & 3 \\
\hline \multicolumn{13}{|c|}{ Simulated dentinal fluid } \\
\hline$\%$ & $3 \cdot 17$ & $2 \cdot 62$ & $3 \cdot 14$ & 2.91 & $2 \cdot 85$ & $3 \cdot 01$ & $21 \cdot 63$ & $28 \cdot 55$ & $33 \cdot 02$ & $13 \cdot 53$ & $24 \cdot 72$ & $27 \cdot 40$ \\
\hline s.d. & $0 \cdot 66$ & $0 \cdot 21$ & $0 \cdot 13$ & $0 \cdot 04$ & $0 \cdot 12$ & $0 \cdot 17$ & $0 \cdot 46$ & $0 \cdot 85$ & $2 \cdot 04$ & $2 \cdot 04$ & $1 \cdot 21$ & 3.99 \\
\hline$r$ & $20 \cdot 1$ & $8 \cdot 0$ & $4 \cdot 1$ & $1 \cdot 4$ & $4 \cdot 2$ & $5 \cdot 6$ & $2 \cdot 1$ & $3 \cdot 0$ & $6 \cdot 2$ & $15 \cdot 1$ & 0.05 & $0 \cdot 15$ \\
\hline \multicolumn{13}{|l|}{ Water } \\
\hline$\%$ & $1 \cdot 56$ & 1.59 & 1.68 & $2 \cdot 07$ & $2 \cdot 01$ & $2 \cdot 15$ & $35 \cdot 70$ & $43 \cdot 18$ & $48 \cdot 58$ & $28 \cdot 75$ & $29 \cdot 89$ & $32 \cdot 24$ \\
\hline s.d. & 0.05 & $0 \cdot 10$ & 0.06 & $0 \cdot 01$ & 0.03 & 0.05 & $1 \cdot 10$ & $3 \cdot 24$ & 0.42 & 0.69 & $1 \cdot 16$ & $1 \cdot 26$ \\
\hline$r$ & $3 \cdot 2$ & $6 \cdot 3$ & $3 \cdot 6$ & $0 \cdot 5$ & $1 \cdot 5$ & $2 \cdot 3$ & $3 \cdot 1$ & $7 \cdot 5$ & $0 \cdot 9$ & $2 \cdot 4$ & 3.9 & $3 \cdot 9$ \\
\hline
\end{tabular}

one-third of the bottles and samples, chosen by random selection, were removed from the shaker water-bath.

At the end of the first, second, and third months, the samples were removed from their bottles and transferred to numbered sterile bottles containing $\mathrm{CaSO}_{4}$ desiccant. In order to reach constant weight the samples were desiccated for 60 days before they were weighed. The percentage loss was calculated after subtracting the weight of the stainless steel wires.

\section{Results}

The percentage loss of each sample set and their standard deviations are shown in Table 2. A three-way analysis of variance (ANOVA) on dental cement bases, fluid, and time was performed to test for differences in percentage loss. If a significant $F$-statistic occurred, the least difference test was applied to determine which means were significantly different. All tests were performed using a significance level of $P \leqslant 0.05$.

For the zinc oxide and eugenol samples (Fynal and Cavitec), the ANova revealed no significant difference with time. Significant interaction, however, was observed when dental cement bases and fluids were compared (Table 3). Because no significant time interaction was noted, all the samples of Fynal from the first, second and third month were pooled, as were those for Cavitec.

The least difference test revealed that there was a significant difference in

Table 3. Statistically significant solubility differences between zinc oxide-eugenol cement bases in water and simulated dentinal fluid

\begin{tabular}{lrrrr}
\hline & $\begin{array}{r}\text { Cavitec } \\
\text { (water) }\end{array}$ & $\begin{array}{r}\text { Fynal } \\
\text { (water) }\end{array}$ & $\begin{array}{r}\text { Fynal } \\
\text { (fluid) }\end{array}$ & $\begin{array}{r}\text { Cavitec } \\
\text { (fluid) }\end{array}$ \\
\hline Cavitec (water) & - & $*$ & $*$ & $*$ \\
Fynal (water) & $*$ & - & $*$ & $*$ \\
Fynal (fluid) & $*$ & $*$ & - & - \\
Cavitec (fluid) & $*$ & $*$ & - & - \\
\hline
\end{tabular}

* Indicates statistically significant differences in the mean loss of dental cement bases (time was not a factor for zinc oxide-eugenol cement bases). 
Table 4. Statistically significant solubility differences between Dycal (D) and Life (L) in water (W) and in simulated dentinal fluid (F) for one (1), two (2) and three (3) months

\begin{tabular}{lrrrrrrrrrrrr}
\hline & LF1 & DF1 & LF2 & LF3 & DF2 & LW1 & LW2 & LW3 & DF3 & DW1 & DW2 & DW3 \\
\hline LF1 & & $*$ & $*$ & $*$ & $*$ & $*$ & $*$ & $*$ & $*$ & $*$ & $*$ & $*$ \\
DF1 & $*$ & & & $*$ & $*$ & $*$ & $*$ & $*$ & $*$ & $*$ & $*$ & $*$ \\
LF2 & $*$ & & & & $*$ & $*$ & $*$ & $*$ & $*$ & $*$ & $*$ & $*$ \\
LF3 & $*$ & $*$ & & & & & & & $*$ & $*$ & $*$ & $*$ \\
DF2 & $*$ & $*$ & $*$ & & & & & & $*$ & $*$ & $*$ & $*$ \\
LW1 & $*$ & $*$ & $*$ & & & & & & $*$ & $*$ & $*$ & $*$ \\
LW2 & $*$ & $*$ & $*$ & & & & & & $*$ & $*$ & $*$ & $*$ \\
LW3 & $*$ & $*$ & $*$ & & & & & & & $*$ & $*$ & $*$ \\
DF3 & $*$ & $*$ & $*$ & $*$ & $*$ & $*$ & $*$ & & & & $*$ & $*$ \\
DW1 & $*$ & $*$ & $*$ & $*$ & $*$ & $*$ & $*$ & $*$ & & & $*$ & $*$ \\
DW2 & $*$ & $*$ & $*$ & $*$ & $*$ & $*$ & $*$ & $*$ & $*$ & $*$ & & $*$ \\
DW3 & $*$ & $*$ & $*$ & $*$ & $*$ & $*$ & $*$ & $*$ & $*$ & $*$ & $*$ & \\
\hline
\end{tabular}

* Statistically significant differences in the mean loss of dental cement bases.

solubility between Cavitec in water and Fynal in water, Fynal in simulated dentinal fluid, and Cavitec in simulated dentinal fluid. Also, Fynal in water produced significantly different results from all the other groups. There was, however, no significant difference between the Fynal or Cavitec groups in simulated dentinal fluid.

For the calcium hydroxide materials (Life and Dycal) the three-way analysis of variance revealed significant interactions, and the least difference test was performed. The conditions where the calcium hydroxide bases were statistically different are presented in Table 4.

\section{Discussion}

The 23-24-h immersion time of the ADA specification tests for cement solubility is well within acceptable limits for zinc oxide-eugenol cement bases, since the zinc oxide-eugenol samples only dissolved initially and then remained stable for the remainder of the study. Solubility at periods longer than 1 month proved not to be significantly different for zinc oxide-eugenol products. The solubility in water of the calcium hydroxide product, Life, was also unrelated to the length of testing.

Zinc oxide-eugenol samples appeared to be less stable in simulated dentinal fluid than in water, suggesting that testing in water may indicate a lower dissolution rate than occurs in the clinical situation. Calcium hydroxide samples, in contrast to the zinc oxide-eugenol products, appeared to be more soluble in water than in simulated dentinal fluid. Testing these materials in water as recommended by ADA specifications would indicate they are more soluble than in a clinical situation. Also, Dycal was more soluble than Life when evaluated over a prolonged period.

The clinical relevance of these results may lie in the application of a particular cement base. A base selected for strength and mass should be relatively insoluble and possess great strength. A base selected for medicinal properties, however, should have some dissolution at the vital dentine base interface. If this material is relatively insoluble, ion exchange through the dentinal tubules to the odontoblastic layer may be impeded, with decreased amounts of secondary dentine being formed. 


\section{Conclusion}

The ADA solubility tests may not provide a valid evaluation of the solubility of zinc oxide-eugenol or calcium hydroxide products since these tests use distilled water as the medium. Zinc oxide-eugenol products have higher solubilities in simulated dentinal fluid than distilled water, and calcium hydroxide products have lower solubilities in simulated dentinal fluid than distilled water.

The length of time specified in the ADA solubility tests appears adequate for testing zinc oxide-eugenol products because perceptible dissolution occurred only in the first month. Calcium hydroxide products, however, continued to dissolve for 3 months longer than the study.

American Dental Association specifications for solubility should be revised to include longer periods of time, an agitation process, and should use a fluid medium that more closely simulates physiological fluid.

\section{Acknowledgments}

This research was supported by the U.S. Army Institute of Dental Research. The opinions or assertations contained herein are the private views of the authors and are not to be construed as official or as reflecting the views of the Department of the Army or the Department of Defense (AR360-50).

\section{References}

American Dental Association (1986) Specification no. for dental zinc phosphate cements. American Dental Association, Chicago, Illinois.

Haldi, J., Wynn, W. \& Culpepper, W.D. (1961) Dental pulp fluid. I. Relationship between dental pulp fluid and blood plasma in protein, glucose, and inorganic element content. Archives of Oral Biology, 3, 201.

Kreudenstein, S. (1958) Contributions to biochemistry of dental lymph. New York State Dental Journal, 24, 343.

Lewin, D.A. (1980) Disappearing dycal (letter to the Editor). British Dental Journal, 148, 32.

McCABE, J.F. (1982) Solubility tests for dental cements. Journal of Dental Research, 61, 331.

Pulver, J.C. \& Rossington, D.R. (1970) Solubility of a silicate cement. Journal of Dental Research, 49, 1530.

Stuben, J. \& Kreudenstein, S. (1956) Dentinbstoffwechselstudien V. Mitteilungen Papierchromatographische Untersuchungen uber den Gehalt an freien Aminosauren im Dentinliquor menschlicher Zahne. Deutsche Zahnaerzliche Zeitschrift, 11, 1448.

Walls, A.W.G., McCabe, J.F. \& Murray, J.J. (1985) An erosion test for dental cements. Journal of Dental Research, 64, 1100.

Wilson, A.D. (1976) Specification test for the solubility and disintegration of dental cements: a critical evalation of its meaning. Journal of Dental Research, 55, 721. 
This document is a scanned copy of a printed document. No warranty is given about the accuracy of the copy. Users should refer to the original published version of the material. 